The University of Southern Mississippi

The Aquila Digital Community

Faculty Publications

$1-1-2014$

\title{
An Examination of Potential Attractions of Women's Marital Infidelity
}

Michelle M. Jeanfreau

University of Southern Mississippi, michelle.jeanfreau@usm.edu

Anthony P. Jurich

Kansas State University

Michael D. Mong

University of Southern Mississippi, Michael.Mong@usm.edu

Follow this and additional works at: https://aquila.usm.edu/fac_pubs

Part of the Social and Behavioral Sciences Commons

\section{Recommended Citation}

Jeanfreau, M. M., Jurich, A. P., Mong, M. D. (2014). An Examination of Potential Attractions of Women's Marital Infidelity. American Journal of Family Therapy, 42(1), 14-28.

Available at: https://aquila.usm.edu/fac_pubs/7962

This Article is brought to you for free and open access by The Aquila Digital Community. It has been accepted for inclusion in Faculty Publications by an authorized administrator of The Aquila Digital Community. For more information, please contact Joshua.Cromwell@usm.edu. 
An Examination of Potential Attractions of Women's Marital Infidelity

Michelle M. Jeanfreau ${ }^{1}$

Anthony P. Jurich ${ }^{2}$

Michael D. Mong ${ }^{3}$

${ }^{1}$ Visiting Assistant Professor, Department of Child and Family Studies, The University of Southern Mississippi, Long Beach, MS.

${ }^{2}$ Professor, School of Family Studies, Kansas State University, Manhattan, KS.

${ }^{3}$ Assistant Professor, Department of Psychology, The University of Southern Mississippi, Long Beach, MS. 


\begin{abstract}
This study used a qualitative approach as a means of exploring women's potential attractions in the participation of marital infidelity. Due to the growing prevalence and potential negative effects of marital infidelity, it is important for both clinicians and researchers to understand its occurrence. This study focused on examining the process an individual goes through when making the decision to have an affair, specifically, the individual's attractions to having a marital affair. Semi-structured interviews were conducted with four female participants who had participated in marital infidelity. The interviews were audio taped, transcribed, and analyzed using the transcendental phenomenological model (Moustakas, 1994). All four women reported developing relationships, outside of their marriage, either with exflames, old friends, or new friends, all of whom became their affair partner. They also reported the support of family and/or friends for the extramarital relationship, along with receiving positive attention from their affair partner. Clinical and research implications are discussed as well as the limitations of the current study.
\end{abstract}


An Examination of Potential Attractions of Women's Marital Infidelity

All individuals have their own conceptions of what marital infidelity means. Recently, the definition of marital infidelity has expanded to include a wide range of behaviors. To some marital infidelity is having a sexual relationship outside of the marriage. Others include behaviors such as cybersex, viewing pornography, varying degrees of nonsexual physical intimacy, and even emotional intimacy with another person to the detriment of the primary relationship (Hertlein, Wetchler, \& Piercy, 2005). For the purpose of the current study, marital infidelity is defined as a secret sexual, romantic, or emotional involvement that violates the commitment to the marital relationship (Blow \& Hartnett, 2005). Estimates of marital infidelity vary widely among American couples ranging from $26 \%$ to $70 \%$ for women and from $33 \%$ to $75 \%$ for men (Eaves \& Robertson-Smith, 2007). Several different models have been developed to explain the incidence of marital infidelity, based on characteristics of the marital relationship. Need fulfillment (Drigotas \& Rusbuilt, 1992), the self-expansion model (Aron \& Aron, 1996), the investment model (Digotas \& Barta, 2001), the deficit model (Thompson, 1984) and the personal growth model (Boekhout, Hendrick \& Hendrick, 2000) all associate characteristics within the marriage as the cause for marital infidelity. Each model is described in greater detail below.

\section{Need Fulfillment}

Drigotas and Rusbuilt (1992) identified seven needs that relationships help individuals meet:

sexual needs, intimacy (self-disclosure), companionship needs (joint activities), intellectual involvement needs (sharing ideas, discussing values and attitudes), emotional involvement needs (one's sense of emotional connection), security needs (depending on the relationship to add predictability and contentment), and self-worth needs (a relationships that makes a person feel good about him or herself). It has been proposed that the possibility of fulfilling these needs forms the basis of an attraction (Lewin, 1942) toward one's spouse. If there is an area in the relationship that is unable to fulfill a certain need, it is possible that the partner with the unfulfilled need will be more likely to give him or herself permission to have the need fulfilled by someone else, which may lead to marital infidelity. 


\section{Investment Model}

The investment model identified the process by which individuals become committed to their relationships and the forces that serve to make an individual more or less committed (Drigotas \& Barta, 2001). Drigotas and Barta (2001) identified the forces as follows: satisfaction (how happy the individual is with the relationship), alternative quality (potential satisfaction provided outside the relationship), and investments (things the individual would lose if the relationship ended). According to this model high levels of satisfaction and investments in the relationship will lead to greater commitment; whereas, high levels of alternative quality will lead to less commitment in the relationship (Campbell \& Foster, 2002). More satisfaction and investment in the marital relationship would indicate a greater attraction to the spouse. High investment within the marriage would act like a barrier to keep the spouse from seeking others. In contrast, lower satisfaction in the marriage and higher alternative quality would increase attraction outside the marriage. Indeed, Beach, Jouriles, \& O’Leary (1985) determined that when comparing couples with marital infidelity issues and couples with other marital problems, the couples with infidelity as a primary issue had a significantly lower level of commitment to the relationship than their non-infidelity counterparts.

\section{Deficit Model}

The deficit model suggests that individuals begin to have extramarital affairs due to problems and dissatisfactions in their marriage (Thompson, 1984; Glass \& Wright, 1985). This marital dissatisfaction makes alternatives look more desirable by comparison. Thompson (1984) identified emotional relating, sexual relating, and communicating as the three major areas of relationship problems. Partners who feel unaccepted, discouraged, unsupported, and not respected within the relationship will suffer emotionally. Those who are unhappy with their ability to give and/or receive sexual satisfaction will suffer sexually (Thompson et. al., 2011). Furthermore, relationships with limited honesty and openness will suffer from communication issues (Thompson, 1984). Thompson (1984) also stated that, based on previous research findings, "the lower self-reported marital satisfaction and the lower the frequency and quality of marital 
intercourse, the more likely the occurrence of extramarital sex" (p. 246). It is important to recognize that the processes occurring in a martial relationship may affect ones view of marital infidelity.

\section{Personal Growth/Self Expansion Model}

The final model used in explaining the occurrence of marital infidelity is the personal growth model which suggests that individuals engage in extramarital behaviors to enhance their sense of self (Boekhout, Hendrick, \& Hendrick, 2000, (Aron \& Aron, 1996; Aron, Norman, \& Aron, 1998 Lewandowski and Ackerman, 2006). Boekhout et. al. (2000) stated that individuals look to a wide range of activities and companions as a way of increasing their self-discovery. If individuals find themselves in a marriage that does not encourage self-discovery, they may be attracted to the idea of marital infidelity as a way of finding someone who will partake in different activities with them as a means of affirming their quest for self-discovery. Bukstel, Roeder, Kilmann, Laughlin and Sotile (1978) sought to determine whether or not college students would project future extramarital sexual behavior and identify the variables that might influence the projections. The results indicated that individuals who sought a variety of premarital sexual partners were more likely to project that they would seek a variety of sexual partners after marriage and they expected to find extramarital sex: (1) more emotionally and sexually satisfying than marital relations, (2) more adventurous (3) likely to increase feelings of inner security (4) increase their social status and (5) increase feelings of independence (Bukstel et al. 1978). These findings may indicate that exposure to more than one premarital sexual partner increases the possibility of nonmonogamous sex during marriage.

Due to the growing prevalence and negative effects of marital infidelity, it is important for both clinicians and researchers to understand its occurrence (Christian-Herman, O'Leary \& Avery-Leaf, 2001). To date, marital infidelity has yet to be studied in a qualitative manner. Qualitative research attempts to understand social processes in context and to understand the meanings of social events for those who are involved in them, which is the largest limitation of survey data (Esterberg, 2002). Thus, the purpose of this study was to use qualitative methodology to examine the process women go through when making 
the decision to have an affair. Furthermore, many of the models discussed have limited research to support them; this study will also attempt to further validate the models through research.

\section{Method}

\section{Participants and Setting}

Purposeful sampling was used to recruit participants from the Gulf Coast region through word of mouth discussion of the research. Participation criteria included the following: participants must (1) be female, (2) be between the ages of 24 and 55, (3) have been involved in a marital affair during some point in their marriage, that (4) was not part of an open marriage agreement, (5) occurred more than one night, and (6) are no longer involved with the affair partner. Finally, (7) it has been at least one year since the affair has ended. All participants in the study provided informed consent consistent with procedures outlined by the university Institutional Review Board.

All four participants were Caucasian females ranging in age from 24-51, reported being married by age 23 , earning less than $\$ 45,000$ a year, being affiliated with the Baptist religion, and subsequently divorced their first husbands following the affair(s). Please refer to Table 1 for additional participant characteristics.

All interviews were conducted by the primary researcher, lasted approximately 45 minutes, held in a neutral location agreed upon by both parties and audio taped.

\section{Research Design}

The approach used in the current study is a qualitative phenomenological research method. Data were collected through the use of semi-structured in-depth interviews. Patton (2002) labeled this type of semi-structured interview the general interview guide approach, which was utilized for the current study. The interview guide was pretested using a pilot mock interview resulting in the rewording of some of the questions and the addition of more questions.

Interview questions focused on the relational background and dynamics of the couple, (e.g. what attracted her to her spouse, marital communication and conflict, how conflict was resolved, and level of 
commitment), the marital affair (e.g. what turned you away from your spouse? How did you meet the affair partner, how they started, continued, and ended the affair, consequences of the affair), relationship with family and friends, stresses (if any) occurring in their life at the time of meeting the affair partner/having the affair, and their thoughts and perceptions about the affair once it had ended.

\section{Data Analysis}

Data analysis included four main aspects: (1) organization of the data, (2) coding and finding themes, patterns, and categories, and (3) determining substantive significance. The method used for coding of the data included the primary steps of the Moustakas transcendental phenomenological model (Moustakas, 1994). During the first step of the analysis, "epoche requires the researcher to look before passing judgment and that judgment of what is "real" or "most real" be suspended until all the evidence is in (Ihde, 1977). The research questions led the analysis.

The second step in the data analysis involved phenomenological reduction, using "bracketing". Within each question the primary researcher began looking for key phrases and statements that spoke directly to the phenomenon (marital infidelity) in question (Denzin, 1989). "Bracketing" included interpreting the meanings of the key phrases and statements, inspecting the meanings for what they revealed about the essential, recurring features of marital infidelity, and finally, offering a tentative statement of marital infidelity, in terms of the essential recurring features (Denzin, 1989).

Imaginative variation included examining all the data as equal, then organizing it into meaningful clusters, eliminating any irrelevant data and identifying the invariant themes within the data (Patton, 2002). Once the themes were identified, the researcher developed "enhance or expanded versions of the invariant themes" (Patton, 2002 p. 486) by looking at them from "different views" (p. 486). The final stage of the analysis was to provide "a synthesis of the meanings and essences of the experience" (Moustakas, 1994 p. 144). This involved the researcher giving a deeper meaning to the participant's experiences as a group by showing patterns and relationships between the participants experiences (Patton, 2002). 


\section{Results}

\section{Friendship}

Although none of the participants discussed actively seeking an affair partner, all four of the participants became actively involved in a relationship outside of their marriages. Each of these relationships began as a friendship, in which, they could disclose issues with which they were dealing in their marriage. Several components played into the participants' attractions to marital infidelity, including; the "just friends" illusion, the support of family and/or friends to have an affair, and the positive attention each of the participants received from the affair partner.

All of the participants interviewed became involved with someone with whom the relationship was previously platonic. Three of the four participants interviewed had an affair with either an "ex-flame" or friend, and the fourth participant developed a friendship with a man that turned into an affair. One of the participants discussed how spending time with friends and reminiscing about the "single days" had sparked her interest about other people. Lexi stated, during this time:

My friends came over and we started drinking...just goofing off and talking about how it would be like if we were single and stuff like that. I went to my friend, to my old friend that I grew up with, that's the one I had the affair with...there wasn't nothing between us, it was just that he was there.

Similarly, Liza stated:

Okay, the guy I cheated on my husband with was a guy who, during our senior year of college, when we were broken up, I kind of, you know, not quite dated him, but you know, almost [to that] point and hung out with him.

When asked if she had a sexual relationship with "this guy", she stated that she was sexually involved with him, but it was in the context of having fun and hanging out, as opposed to dating. Liza went on to say, "I mean the communication continued, even when me and (my boyfriend) got back together, not that often, but you know, like more on a friendly basis." She went on to say, "even when 
(her current husband) picked up on it, he read some e-mails (but) had no clue that anything had happened. I mean it was just innocent." When asked if she felt like she was ever crossing the line of friendship she responded,

I didn't get that feeling.... felt extremely close to him, and it's just from that time period that we dated when [my husband] and I weren't together. We were extremely close during that time, so it was like, I am sure if it's somebody who I just met or some guy, you know I would have felt like conversations would have been crossing the line, but because of the history you're like; well he's been a great friend to me.

Finally, Kara discussed a crush she had in the past with the man who became her affair partner. She discussed keeping in touch with the man, whom she called her "young sweetheart" or crush, "I've always kept in touch, we've always been friends.... and I still keep in touch with him today."

\section{Extramarital Support}

Another similarity between the participants was the support of their family members and/or friends to have a marital affair. Only one of the participants, Liza, did not involve the knowledge or efforts of others. Although she did state, "my sisters knew that we were good friends, so they probably knew that there was an emotional connection there, but they didn't know about the affair." The other three participants had friends and/or family members who supported the affair relationship. Kara explained:

So of course I lied to my momma and daddy, I said I'm going out with my cousin, so they (would) babysit for me cuz I didn't want them to (suspect)....so my cousin, I (would) ride with her, I meet the guy, and anyway...my cousin would cover up for me.

She continued to talk about the close relationship with her cousin and stated that her cousin "was glad because she didn't like my husband...she encouraged me, she's like, 'I'll take you anywhere'. You know, just she would take me to meet him." Lexi stated that two of her sisters-in-law knew about her affair, she said, "One of them would go with me because she had an affair too." When asked about the 
effect it had on her, she stated, "They wanted me to leave. They said, 'you need to get away from [your husband], he's gonna kill you'." Similarly, Isabel stated that she had both friends and family members who knew about her affair and one, in particular, who she stated "told me, 'go ahead'; cuz they was, she was having one....she knew everything I was going through, like I knew everything she was going through."

The influence of ex-flames, friends and family members played a significant role in the opportunity for marital infidelity to occur. For all of the participants, this had an effect on both how they viewed their marital relationship and on their affair relationship as well.

\section{Attention}

The final component that had an effect on the attraction to marital infidelity was the positive attention the participants received from their affair partners.

The level of attention each of the participants received from her affair partners was a common theme for each of the interviewees. Liza explained:

You know, so it's not that I had planned for the affair or thought it was gonna happen, but I at some point, I was more emotionally connect to [the affair partner] than I was to my husband... because I could talk to [him] and you know most of the time [my husband] wasn't giving me five min in a day to talk to him and, if I did, he would just be like tell him what I had to say and it'd be like okay, there was no conversation about anything.

Lexi stated: "I want[ed] somebody in my life that would love me for me. That would just show attention to me, for me, and you know made me feel like I was worthwhile." When asked about the affair, Lexi continued by saying, "I think it was an attention thing....I could go do things and his whole

family accepted me and they accepted my kids." Kara discussed similar attention from her affair partner: I felt like he was giving me the attention that I was not getting from my husband, and like one night we went to, after we ate, we went to the mall and he like bought me clothes and bought me stuff and he was giving me the attention. 
Finally, Isabel explained what attracted her to the idea of having an affair, "I guess the affection that I needed. The touching and feeling and being wanted...the hugging, the holding my hand, just you know."

One of the participants described her participation in the marital affair as a positive experience. It may be important to present this information for two reasons: (1) she was the only participant to report that she would have another affair, and that she had no guilt about her actions, (2) there is previous research to support what she reported (Allen \& Baucom, 2004; Glass \& Wright, 1992). When I asked Kara, if looking back at that time in her life, she would have the affair again she was the only one of the women to say "yes". She stated:

Yes, I would if at that time, I would do it all over again because I look back and it got me out, you know. I feel like that is what really got me out of my marriage. Having the affair showed me that I am a very strong person and I am somebody. The guy I was having the affair with, he like brought the best out in me because he encouraged me...taught me I could be somebody, I could make something of myself. I feel like I need to give the guy credit. He was the solid rock at the time that I stood on and, if it wouldn't have been for him, I would probably still, and I can't say [for sure], be in that relationship.

The support and encouragement the affair partner gave to Kara attracted her to marital infidelity because it made her a stronger person than she was in her marital relationship.

Each of the participants described the positive attention she was getting from what started out as friendship and moved to an affair. None of the participants stated starting a sexual relationship prior to an emotional relationship. The sexual component came after the emotional relationship was established, which served to progress the relationship further. The positive attention each participant received only made the connection in the extramarital relationship stronger because the woman had a shift in focus from the negative qualities in each of their marriages to the positive attention they were getting in the 
extramarital relationship. This allowed the participants to feel satisfaction they were not feeling in their marriage, which made them more committed to developing an extramarital relationship.

These results demonstrate how the participants became involved in marital infidelity, when the dissatisfaction they were feeling in their marriage was replaced with positive attention from a friend or ex-flame. The affair partner was fulfilling needs that were not being met by the participant's husbands. Although each of the participants did not intentionally seek to engage in an extramarital affair, the illusion of being "just friends" with the other person allowed the woman to experience positive attention, which, in turn, pulled them toward an extramarital commitment and made it increasingly difficult to stay committed to the marriage.

\section{Discussion}

Marital infidelity has been a large focus in recent years as previous research has suggested that as many as $50 \%$ of woman and $60 \%$ of men have engage in marital infidelity (Glass \& Wright, 1992; Shackeflord \& Buss, 1997; Treas \& Gieson, 2000). Due to the growing prevalence and negative effects of marital infidelity, it is important for both clinicians and researchers to understand its occurrence (Christian-Herman, O’Leary \& Avery-Leaf, 2001). Thus, the primary goal of this qualitative study was to gain greater insight into the decision-making process of women who have participated in marital infidelity.

All participants interviewed became involved with someone they believed was "just a friend" and three of the four participants had an affair with either an ex-flame or old friend. The participants explained being able to seek comfort in these relationships because they never felt it would lead to anything beyond friendship. Even the one participant who did not have an affair with someone in her past described developing an innocent friendship that turned into marital infidelity. None of the participants set out to have a marital affair. This theme was supported in the literature pertaining to the different types of marital infidelity. Pittman (1989) identified "accidental infidelity" as a type of marital infidelity and defined it as "incidents that were outside the usual patterns of behavior, happening in extraordinary 
situations, or offhandedly and without consideration of the consequences" (p. 135). This type of occurrence is more likely when one or both friends/ex-flames are having marital or relationship problems and their friendship boundaries become blurred because of the unexpected intimacy they are sharing with one another. When the level of intimacy in these friendships surpassed the level of intimacy in their marital relationships, it became an attraction to marital infidelity. Support for the other types of infidelity was not found in this study.

Another similarity between the participants was the support of the participants' family members and/or friends to have a marital affair. Three of the participants had friends and/or family members who supported the affair relationship. This finding was consistent with the results of Atwater (1979) and Zak and colleagues (2002). While the friends and/or family members supported the affair relationship, they did not support the marital relationship, which would have acted as a barrier to marital infidelity. The findings of the current research validate the importance of establishing a network of friends and family members who are supportive of the marital relationship.

The positive attention the participants received from their affair partners was also an attraction to marital infidelity. The four participants described positive attention as things such as: emotional connection, listening, spending time together, being accepted, and physical affection. This allowed the participants to feel satisfaction they were not feeling in their marriage, which made them more committed to developing an extramarital relationship.

According to the investment model, there are forces that serve to make an individual more or less committed (Drigotas \& Barta, 2001) in their marital relationship. In the current study, the results support the investment model as high levels of satisfaction and investments in the relationship likely lead to greater commitment; whereas, high levels of alternative quality likely lead to less commitment in the relationship (Campbell \& Foster, 2002). Each of the participants was receiving higher levels of satisfaction from an extramarital relationship along with having a low level of satisfaction in her marital relationship created an attraction to marital infidelity. 
The final attraction to marital infidelity for the participants was the repulsions within their marriages. The lack of quality time, the inability to solve marital conflict and the lack of attention the participants experienced from their husbands all served to lower the quality of the marital relationship leading to marital dissatisfaction. The marital dissatisfaction the participants experienced, from the repulsions within their marriage, in turn, led to a greater attraction to marital infidelity.

Kara described her participation in the marital affair as a positive experience. This may be important to note for two reasons, (1) she was on the opposite side of the spectrum, compared to the other women in the study and (2) there is previous research (Allen \& Baucom, 2004; Glass \& Wright, 1992) to support what she reported. Individuals, with low levels of self-esteem, will let down their protective barriers around the marriage because an outside individual may make them feel good about themselves and, instead of thinking about the needs of the marriage, they will want to satisfy their own need to gain self-confidence. (Allen \& Baucom, 2004; Glass \& Wright, 1992). Glass and Wright (1992) and Allen and Baucom (2004) identified enhancement of self-confidence and self-esteem as an emotional justification for extramarital behavior.

Although the present study has contributed to the understanding of what may attract women towards marital infidelity, several limitations should be noted. According to Patton (2002), any time qualitative methods are chosen for the research design there are tradeoffs, "there are no perfect research designs" (p.223). Only four participants were included in the study, which is a small sample size. The exploratory method of the study required the use of a homogenous sample to ensure more consistency from case to case to help identify themes and patterns of the women's experience of marital infidelity that were similar and different. Due to the small sample size the participants do not represent the larger population of females. Also, because this was an exploratory qualitative study; no confirmatory results can be given. Researchers should attempt to verify the results in future studies.

Furthermore, this study included only women who had experienced marital infidelity within a heterosexual marriage, which means that the results do not apply to women who cohabitate, are engaged, 
dating, or involved in non-traditional marriages. Replication of this study with populations with diverse aspects may address these issues and increase the generalizability of the results to nonhomogenous samples.

Although this study sought to obtain an accurate description of the participants' experiences, it is possible that interview data limitations, such as distorted responses due to participants' personal views, age differences, anxiety, embarrassment and the participant's ability to recall information from their first marriages may distort the accuracy of the results. The participants' self reports were subjective and it is also possible that some of the participants may not have been as forthcoming, when answering or discussing certain questions. Finally, it is possible that the researcher may have had bias in terms of interpretation of the data. The data analysis required the researcher to become deeply involved in the data. Therefore, it is possible that past experiences and knowledge of the research may have influenced the results.

The present investigation examined the decision-making processes of four women who participated in an extramarital affair. Through the use of in-depth interviews, several themes emerged (friendship, extramarital support and positive attention) as attractions to marital infidelity providing an opportunity to begin to understand the decision making process the women went through when dealing with the conflict of staying committed to their marriage or beginning a marital affair.

\section{Clinical Implications}

In order for clinicians to increase the aversion to marital infidelity, it is important to discuss the role that marital infidelity has taken in our society and encourage the clients to reiterate the moral values that guide their lives. Discussing marital infidelity is important, because most clients will think it is not an issue for them, because they do oppose it. The reality is that infidelity happens because of a lack of acknowledgement to the possibility of its occurrence. If clinicians would take the time to openly discuss with clients the prevalence of marital infidelity, it would open the couple up to discussing, the negative consequences of infidelity on their marriage and family, along with the message and model they would be 
conveying to their children. Clinicians should help the couple strengthen the view that marital infidelity has the ability to cause distress to their marriage and their family as a whole. Discussing infidelity with clients will also allow clinicians to talk about ways to strengthen the marital relationship so infidelity does not become a symptom of problems within the relationship.

It is important for clinicians to recognize what attracts individuals to marital infidelity because this will enable them to help individuals and couples establish appropriate boundaries outside of their marital relationship. According to the Structural Family Therapy model establishing clear boundaries both in and outside the marital relationship will modify the way people relate to one another (Piercy, Sprenkle, Wetchler, \& Associates, 1996). Three of the participants became involved in an extramarital affair with ex-flames or old friends, and one participant developed a friendship that led to a marital affair. It is important that clinicians educate clients on the potential harm of maintaining such extramarital relationships and help them establish appropriate boundaries to protect their marital relationship. Many times individuals turn to a person outside of their marriage to discuss emotional or intense events that may be occurring within their relationships, also known as triangulation. When another individual is triangled into marital conflict it temporarily stabilizes the marital relationship but does not deal with the issue head on. The marital partner who is discussing issues in their marriage with an outside person may than look to that individual for comfort rather than resolving the issues with their spouse. Clinicians should educate clients on triangulation and friendships outside the marriage to make sure clients understand that friendships, particularly those where there is an attraction or potential for an affair, do not become too personal by limiting the amount of personal and intimate information they share and not placing themselves in harmful positions (e.g. working alone with someone of the opposite sex). The clinician might establish a rule such as: never discuss with someone outside the marriage a topic which has not been discussed previously with the spouse within the marriage.

Another important factor is having friends and family members who are friends of the marriage. It is important that clinicians help clients recognize individuals who may be damaging their marital 
relationship and encourage them to surround themselves with people who are supportive of the marital relationship.

The women in the current study experienced positive attention from the affair partner. Clinicians should again focus on boundary development and increase the amount of positive attention within the marriage. This would mean facilitating discussions between the couple about their wants and needs from the marital relationship. According to Lewandowski and Ackerman (2006) when a relationship is not fulfilling needs including intimacy, companionship, security and emotional involvement, individuals are more likely to engage in extramarital relationships. It is particularly important for a woman to feel a sense of security and be in an intimate relationship with a reliable individual that makes her life stable and comfortable (Lewandowski \& Ackerman, 2006). Clinicians should also focus on trust building in the relationship to enhance the sense of security. Prevention of marital infidelity would be the ideal but is not always the case. Helping couples recover from an affair is also important, all of the women who participated in the study ended up divorced from their spouses.

Treating couples who have experienced infidelity in their relationship is considered, by therapists, one of the most difficult treatments (Whisman, Dixon, \& Johnson, 1997). Although there is not much empirical research to support treatment models, forgiveness based treatments have been shown to be effective with couples who jointly want to repair their marriage and stay together. It is important to point out that for those couples who do decide to repair their marital relationship it will be a long process that leads to forgiveness (Bagarozzi, 2008; Diblasio, 2000; Stefano \& Oala, 2008; Olmstead, Blick \& Mills, 2009; Olson, Russell, Higgins-Kessler \& Miller, 2002). 


\section{References}

Allen, E. S., \& Baucom, D. H. (2004). Adult attachment and patterns of extradyadic involvement. Family Process, 43, 467 - 488.

Aron, E. N., \& Aron, A. (1996). Love and expansion of the self: The state of the model. Personal Relationships, 3, 45-58.

Aron, A., Norman, C. C., \& Aron, E. N. (1998). The self-expansion model and motivation. Representative Research in Social Psychology, 22, 1-13.

Atwater, L. (1979). Getting Involved: Women's transition to first extramarital sex. Alternative Lifestyles, 2, 33 - 68.

Bagarozzi, D. A. (2008). Understanding and treating marital infidelity: A multidimensional model. The American Journal of Family Therapy, 36, 1-17.

Beach, S. R. H., Jouriles, E. N., \& O'Leary, K. D. (1985). Extramarital sex: Impact on depression and commitment in couples seeking marital therapy. Journal of Sex and Marital Therapy, 11, 99-108.

Blow, A. J., \& Hartnett, K. (2005a). Infidelity in committed relationships I: A methodological review. Journal of Marital and Family Therapy, 31(2), 183-216.

Boekhout, B., Hendrick, S. S., \& Hendrick, C. (2000). The loss of loved ones: The impact of relationship infidelity. In J. H. Harvey \& E. D. Miller (Eds.), Loss and Trauma, General and Close Relationship Perspectives. Ann Arbor MI: Edwards Brothers.

Bukstrel, L. H., Roeder, G. D., Kilmann, P. R., Laughlin, J., \& Sotile, W. M. (1978). Projected extramarital sexual involvement in unmarried college students. Journal of Marriage and The Family, 40, 337-340.

Campbell, W. K., \& Foster, C. A. (2002). Narcissism and commitment in romantic relationships: An investment model analysis. Personality and Social Psychology, 28, 484-495. 
Christian-Herman, J. L., O'Leary, K. D., \& Avery-Leaf, S. (2001). The impact of severe negative events in marriage on depression. Journal of Social and Clinical Psychology, 20, 24-40.

Denzin, N. K. (1989). Interpretive Interactionism. Newbury Park, CA: Sage.

DiBlasio, F. A. (2000). Decision-based forgiveness treatment in cases of marital infidelity. Psychotherapy, 37 149-158

Drigotas, S.M., \& Rusbult, C. E. (1992). Should I stay or should I go? A dependence model of breakups. Journal of Personality and Social Psychology, 62, 62 - 87.

Drigotas, S. M., \& Barta W. (2001). The cheating heart: Scientific explorations of infidelity. Current Directions in Psychological Science, 10, 177-180.

Eaves, S., \& Robertson-Smith, M. (2007). The relationship between self-worth and marital infidelity: A pilot study. The Family Journal, 15, 382-386.

Esterberg, K. G. (2002). Qualitative Methods in Social Research. Boston: McGraw Hill.

Glass, S. P., \& Wright, T. L. (1985). Sex differences in types of extramarital involvement and marital dissatisfaction. Sex Roles, 12, 1101-1119.

Glass, S. P., \& Wright, T. L. (1992). Justifications for extramarital relationships: The association between attitudes, behaviors, and gender. Journal of Sex Research, 29, 1-27.

Hertlein, K. M., Wetchler, J. L., \& Piercy, F. P. (2005). Infidelity: An overview. Journal Of Couple \& Relationship Therapy, 4, 5-16.

Ihde, D. (1977). Experimental Phenomenology. New York: Putman.

Lewandowski, J. G. W., \& Ackerman, R. A. (2006). Something's missing: Need fulfillment and self-expansion as predictors of susceptibility to infidelity. The Journal of Social Psychology, 146, $389-403$.

Lewin, K. (1942). Field theory and learning. In The Psychology of Learning, the Yearbook of the National Society for the Study of Education.

Moustakas, C. (1994). Phenomenological Research Methods. Thousand Oaks, CA: Sage. 
Olmstead, S. B., Blick, R. W., \& Mills, L. I. (2009). Helping cocuples work toward the forgiveness of marital infidelity: Therapists' Perspectives. The American Journal of Family Therapy, 37, 48-66.

Olson, M. M., Russell, C.S., Higgins-Kessler, M., \& Miller, R. B. (2002). Emotional processes following disclosure of an extramarital affair. Journal of marital \& Family Therapy, 28, 423-434

Patton, Q. (2002). Qualitative Research \& Evaluation Methods. Thousand Oaks: Sage Publications.

Piercy, F. P., Sprenkle, D. H., Wetchler, J. L., \& Associates (1996). Family Therapy Sourcebook (2 ${ }^{\text {nd }}$ Ed.). New York: The Guildord Press.

Pittman, F. I. (1989). Private Lies: Infidelity and the Betrayal of Intimacy. New York: Norton.

Shackelford, T. K., \& Buss, D. M. (2000). Marital satisfaction and spousal cost-infliction. Personality and Individual Differences, 28, 917-928.

Stefano, J. D., Oala, M. (2008). Extramarital affairs: basic considerations and essential tasks in clinical work. The Family Journal, 16, 13-19.

Thompson, W. K., Charo, L., Vahia, I. V., Depp, C., Allison, M., \& Jeste, D. V. (2011). Association between higher levels of sexual function, activity, and satisfaction and self-rated successful aging in older postmenopausal women. Journal Of The American Geriatrics Society, 59, 1503-1508.

Thompson, A. P. (1984). Emotional and sexual components of extramarital relations. Journal of Marriage and The Family 46, 35 - 42.

Treas, J., Giesen, D. (2000). Sexual infidelity among married and cohabiting Americans. Journal of Marriage and The Family, 62, 48 - 60.

Zak, A., Coulter, C., Giglio, S., Hall, J., \& Sanford, S. (2002). Do his friends and family like me? Predictors of infidelity in intimate relationships. North American Journal of Psychology, 4, 287 290. 
Table 1. Participant characteristics

\begin{tabular}{llllll}
\hline Participant & Age & $\begin{array}{l}\text { Age at time } \\
\text { of } 1^{\text {st }} \text { marriage }\end{array}$ & $\begin{array}{l}\text { \#of years married } \\
\text { when affair began }\end{array}$ & $\begin{array}{l}\text { \#of marital } \\
\text { affairs }\end{array}$ & \#of children \\
\hline Lexi & 51 & 19 & 6 years & a few & 3 \\
Isabel & 48 & 18 & 3 years & 2 & 5 \\
Liza & 24 & 23 & 7 months & 1 & 0 \\
Kara & 36 & 19 & 6 years & 1 & 2 \\
\hline
\end{tabular}

